\title{
An approach for standardization of semantic models for building renovation processes
}

\author{
C. Mirarchi ${ }^{1 *}$, M.N. Lucky ${ }^{1}$, S. Ciuffreda ${ }^{1}$, M. Signorini ${ }^{1}$, S. Lupica Spagnolo ${ }^{1}$, C. Bolognesi ${ }^{1}$, B. Daniotti ${ }^{1}$, A. Pavan $^{1}$ \\ ${ }^{1}$ Politecnico di Milano, Department of Architecture, Built environment and Construction engineering, Milan, Italy - \\ (claudio.mirarchi@polimi.it, meherunnesa.lucky@polimi.it, simone.ciuffreda@polimi.it, martina.signorini@polimi.it, \\ sonia.lupica@polimi.it, cecilia.bolognesi@polimi.it, bruno.daniotti@polimi.it, alberto.pavan@polimi.it)
}

Commission IV, WG IV/2

KEY WORDS: Semantic modelling, Ontologies, BIM, Standardization, linked data

\begin{abstract}
:
The design and maintenance of buildings and infrastructures relies on digital tools such as Computer-Aided Design (CAD), Building Information Modelling (BIM) methods, Geographic Information System (GIS) datasets and other kinds of digital representation of knowledge. The innovations in digital technologies in Architecture, Engineering, Construction and Operations (AECO) sector are not just related to the enhancement of consolidated processes, but they open new collaboration methods and integration with other Information and Communication Technologies (ICT) such as Internet of Things (IoT), additive manufacturing, automation, augmented reality and artificial intelligence. As domain-specific software solutions are expanding their features over different sources and datasets, the need for integration and standardization of information storage and exchange arises. Semantic Web technologies are one of the emerging solutions for solving such issues, as they offer the possibility to combine data from diverse data models and multiple domains using the web. Among the ontologies developed in the last decade for the construction sector, one specific reference should be made on the ifcOWL, an IFC-based ontology representing the most used data schema industry. Nonetheless, from the standardization point of view, so far ontologies have not been considered among the standard methods for information exchange in the AEC, unlike in other sectors (e.g. ISO 15926 was firstly developed for the integration of life cycle data for process plants of oil and gas facilities). This paper aims at showing a standardization and harmonization perspective for ontologies in the AECO industry, starting from the results achieved in the BIM4EEB project.
\end{abstract}

\section{INTRODUCTION}

Actors of the Architecture, Engineering, Construction and Operations (AECO) industry exchange heterogeneous information among multiple stakeholders, using tools and datasets of different nature. The development of construction projects has shifted from paper-based drawings to Computer Aided Design (CAD) in the last decades, but the industry is still struggling to solve the communication issues between the many users of building design projects information and the interoperability between the tools. Building Information Modelling (BIM) represents the most effective attempt to improve information management in construction. It consists in a set of methods, technologies and processes designed for the collaboration of multiple stakeholders along the entire life cycle of a built asset. The ISO 19650-1:2018 (ISO, 2018b) defines it as the "use of a shared digital representation of a built asset to facilitate design, construction and operation processes to form a reliable basis for decisions".

Among the digital approaches applied in the construction field, BIM has gained a leading role in research trends. Recent studies identify and recognize how the implementation of BIM has become crucial for the effectiveness of interventions on the built environment (Won, et al., 2013). In fact, according to the NBS 2019 report (NBS, 2019), most designers are convinced that BIM usage can bring to a strong reduction in time and cost for the completion of new or renovation projects. Over the years, the inclusion of BIM in national regulations, the intense work of standardization bodies and the diffuse research activities have helped the spread of BIM tools and methods, even if small and medium enterprises (SMEs) are still struggling in the adoption of BIM practices and tools due to lack of information, education and/or confidence in these processes (NBS, 2019).
Nonetheless, construction processes are characterised by a high level of complexity, a high number of expertise involved producing one-of-a-kind products. Most of the software solutions available on the market are developed to undertake specific tasks of a design project. The workflow of coordination between the output of BIM application suffers diffused data gaps because of different conceptual data models. Hence the need for a better knowledge management in the construction sector arises. The trends of research in this topic show that BIM is one of the domains of digital transformation, together with other technologies and approaches that should be oriented to generic holistic knowledge management (Mirarchi, 2019). The complexity of the process and the related solutions involving both humans and machines suggests a multi-layer strategy of research stages (Liu, et al., 2019). In their work, Liu et al. propose a framework of three main streams of research: the formulating stage, the accelerating stage and the tranforming stage. The first term summarizes reviews and conceptual frameworks in BIM research, made of theoretical study of origins and emerging scenarios of BIM. The second one relates to the technologies for the widespread of the transition, i.e. the integration of BIM and other related technologies like GIS, code checking, clash detection etc. The transforming stage, instead, focuses on the emerging scenarios of evolution of BIM exploiting new information and communication technologies (ICT). In particular, knowledge representations using Semantic Web (Berners-Lee, et al., 2001) technologies belong to this last relevant area of research.

Coherently with the concept of BIM level (NBS, 2019), Linked Data technologies represent the technologies for the industry to evolve from a federated building information model level to an ontology-enabled full integrated model for building information 
management. The work towards the description of BIM data through Linked Data technologies started with the translation of the Industry Foundation Classes (IFC) schema to Web Ontology Language (OWL) (Beetz, et al., 2009). However, the low expressivity and the complexity of the IFC data schema hindered the full exploitation of the ontology capabilities. Relevant efforts are represented by the outcomes of the Linked Building Data (LBD) Community Group (W3C, 2014). The group is developing use cases and requirements for linked data applications across the life cycle of building and has delivered important results like the Building Topology Ontology (bot) (Rasmussen, et al., 2017).

This paper investigates the topic of knowledge management in the construction sector by proposing an approach for the definition and harmonization of an ontology framework for the construction industry, starting from the first outcomes of the EU-funded research project BIM4EEB (BIM4EEB, 2019).

The paper is organized as follows. Section 2 presents the state of the art in the research field of semantic modelling for BIM data. Section 3 introduces the methods for ontology development and harmonization. Section 4 reports about the application of such methods to the case study of the BIM4EEB project, highlighting its relevance for harmonization of both standards and ontologies Finally, section 5 summarises the outcomes of this research and the future developments.

\section{STATE OF THE ART}

AECO sector is a project-based process where different stakeholders need to interact throughout different stages, from pre-design and design phases to construction, operation, maintenance and finally disposal of a built asset. Also, the continuous specialization of the tasks highlights the need for specific tools, which may operate on different platforms, represent data with different schemas and exchange information in different ways, causing interoperability issues.

Different kinds of data require different exchange and collaboration methods, adding complexity to interoperability. In investigating for interoperability problems, Lee (Lee, 2011) ordered the causes in three main categories: technical, procedural and unwillingness. As BIM data standards cannot interfere with such human factors, the role of standardization bodies is limited to the first two previously cited categories, described by the following issues:
1. $\quad$ Limited coverage of a data model;
2. Translator problems;
3. Software bugs or implementation issues;
4. Software domain problems.

The kind of information exchanged in construction processes may vary from images, documents, models, etc. Some of the most common file formats used in AECO sector applications are .jpeg and .gif for raster images, .pdf for documents, .dxf, .dwg, .3ds, .obj for 2D or 3D surfaces, .ifc, gbXML and others for information models (Eastman, et al., 2018). Apart from the nature of the information, the mean of transport of information is crucial for an effective data exchange. There are three main ways of exchanging data: through direct links between two applications, which make available the model or part of it thanks to specific interfaces; with a file-based exchange method, both on proprietary and open standard formats; and through a database management system (DBMS) (Vries, et al., 1999).
For these reasons, a common data representation and exchange format is needed for a workflow enabling collaboration as BIM adoption suggests. An overview of the standards and their relations analysed in this paper is pictured in Figure 1.

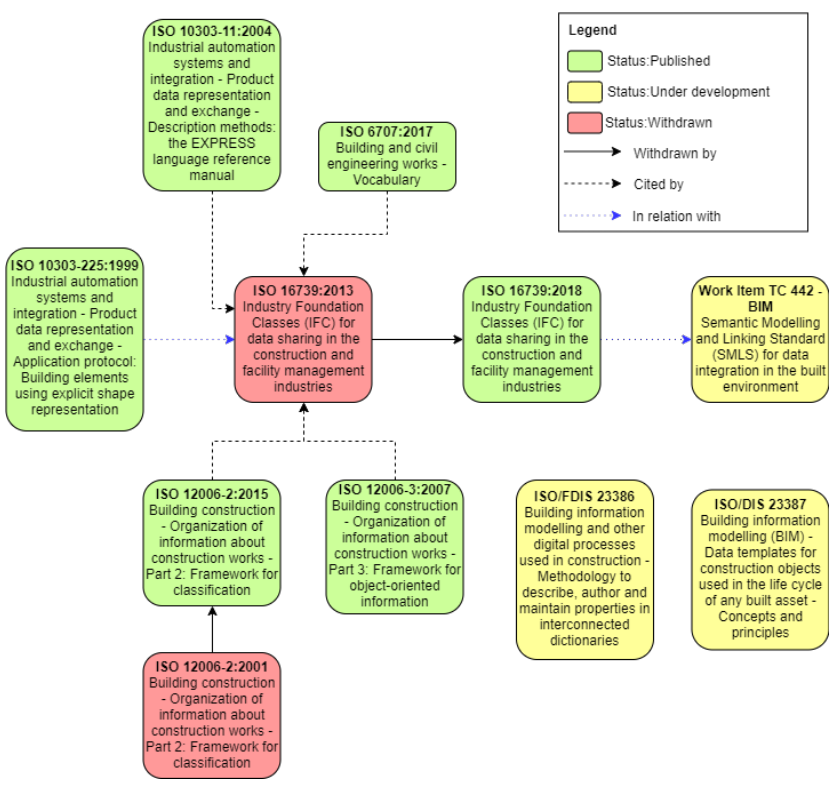

Figure 1 - Framework of the analysed standards (BIM4EEB, 2020b)

The first attempt of the standardization bodies to develop a standard exchange format is the STEP format, initially published in ISO 10303 (ISO, 2004a) in the late 1980s. This standard, also known as ISO STEP, describes information exchange mechanisms and, among its parts, provides a description method, the EXPRESS language, and an implementation method, the STEP format.

Data models were introduced to support product and object model exchanges within different industries, from electronical, mechanical and automotive production, to manufacturing, process plants and furniture production. The different domains are represented thanks to the introduction of Application Protocols (APs), published in the version of 2002. They are the basis for framework of standards for information exchange also in the oil and gas production sector, starting from the ISO 15926-1 (ISO, 2004b) to the other developed parts of this ISO 15926 series or structural steel design and fabrication (CIS/2). ISO 10303 AP 225 - Building elements using explicit shape representation is the product data model for AECO sector inside the framework of ISO STEP, as other data models approved by ISO were originally developed by other organizations.

The sub-committee 15 of the technical committee 59 of ISO (referred as ISO/TC 59/SC 13) has focused the standardization work on the processes of information creation and management of geospatial and built environment data in digital environment. The full list of standards developed by ISO/TC 59/SC 13 is shown in Table 1. This group developed, integrating ISO STEP and other models, several data exchange protocols and standards handling information, semantics and processes of BIM. 


\begin{tabular}{|c|c|c|}
\hline Standard number & Stage & Catalogue \\
\hline ISO 12006-2:2015 & Published & Construction industry \\
\hline ISO 12006-3:2007 & Published & Construction industry \\
\hline ISO/WD 12006-3 & $\begin{array}{l}\text { Under } \\
\text { development }\end{array}$ & Construction industry \\
\hline ISO 12911:2012 & Published & Construction industry \\
\hline ISO/WD 12911 & $\begin{array}{l}\text { Under } \\
\text { development }\end{array}$ & Construction industry \\
\hline ISO 16354:2013 & Published & Construction industry \\
\hline ISO 16739-1:2018 & Published & Construction industry \\
\hline ISO 16757-1:2015 & Published & Construction industry \\
\hline ISO 16757-2:2016 & Published & Construction industry \\
\hline ISO 29481-1:2016 & Published & Construction industry \\
\hline ISO 29481-2:2012 & Published & Construction industry \\
\hline ISO 19650-1:2018 & Published & $\begin{array}{l}\text { Construction industry, IT } \\
\text { applications in building } \\
\text { and construction industry }\end{array}$ \\
\hline ISO 19650-2:2018 & Published & $\begin{array}{l}\text { Construction industry, IT } \\
\text { applications in building } \\
\text { and construction industry }\end{array}$ \\
\hline ISO/FDIS 19650-3 & $\begin{array}{l}\text { Under } \\
\text { development }\end{array}$ & $\begin{array}{l}\text { Construction industry, IT } \\
\text { applications in building } \\
\text { and construction industry }\end{array}$ \\
\hline ISO/WD 19650-4 & $\begin{array}{l}\text { Under } \\
\text { development }\end{array}$ & \\
\hline ISO/FDIS 19650-5 & $\begin{array}{l}\text { Under } \\
\text { development }\end{array}$ & $\begin{array}{l}\text { Construction industry, IT } \\
\text { applications in building } \\
\text { and construction industry }\end{array}$ \\
\hline ISO 21597-1:2020 & Published & $\begin{array}{l}\text { Construction industry, IT } \\
\text { applications in building } \\
\text { and construction industry }\end{array}$ \\
\hline ISO/DIS 21597-2 & $\begin{array}{l}\text { Under } \\
\text { development }\end{array}$ & $\begin{array}{l}\text { Construction industry, IT } \\
\text { applications in building } \\
\text { and construction industry }\end{array}$ \\
\hline ISO 22263:2008 & Published & Construction industry \\
\hline ISO/CD TR 23262 & $\begin{array}{l}\text { Under } \\
\text { development }\end{array}$ & \\
\hline ISO 23386:2020 & Published & $\begin{array}{l}\text { IT applications in } \\
\text { building and construction } \\
\text { industry }\end{array}$ \\
\hline ISO/FDIS 23387 & $\begin{array}{l}\text { Under } \\
\text { development }\end{array}$ & $\begin{array}{l}\text { Construction industry, IT } \\
\text { applications in building } \\
\text { and construction industry }\end{array}$ \\
\hline ISO 29481-1:2016 & Published & Construction industry \\
\hline ISO 29481-2:2012 & Published & Construction industry \\
\hline
\end{tabular}

Table 1 - Standards developed by the ISO/TC 59/SC 13 Technical committee (1)

Industry Foundation Classes (IFC), standardized in ISO 16739:2018 in its version IFC4 ADD2 TC1 (ISO, 2018a), represents the most used data model in AECO sector. Started as an initiative of the International Alliance for Interoperability (IAI), known from 2005 as buildingSMART, the promoting consortium of software developers and vendors still develops integration of IFC and other standards, like the BIM Collaboration Format (BCF) or the buildingSMART Data Dictionary (bsDD). IFC is a schema enabling fast information exchange with an extensible set of data representation. It is written in EXPRESS language and it is compliant to the ISO

(1) Source: https://www.iso.org/committee/49180/x/catalogue/, accessed on $24 / 04 / 2020$
12006-3 (ISO, 2007) object-oriented framework. It is designed to support all related AECO sub-domains, thus it provides generic definitions of objects and data that can be extended for specific purposes. Its architecture divides entities in four layers (Figure 2):

- Resource layer: it contains 21 entities representing the basic ones.

- Interoperability layer: it is composed of base entities and it defines basic objects used in AECO such as doors, windows, walls, processes and management elements, etc.

- Domain layer: it contains domain specific extensions of the objects and relations of other layers.

- Core layer: it contains the highest-level abstract entities, such as IfcRoot, which assigns elements the Globally Unique IDs (GUIDs) and other data.

IFC represents a logical schema in the three-level architecture schema of databases, also known as the ANSI/X3/SPARC architecture (ANSI/X3/SPARC, 1975).

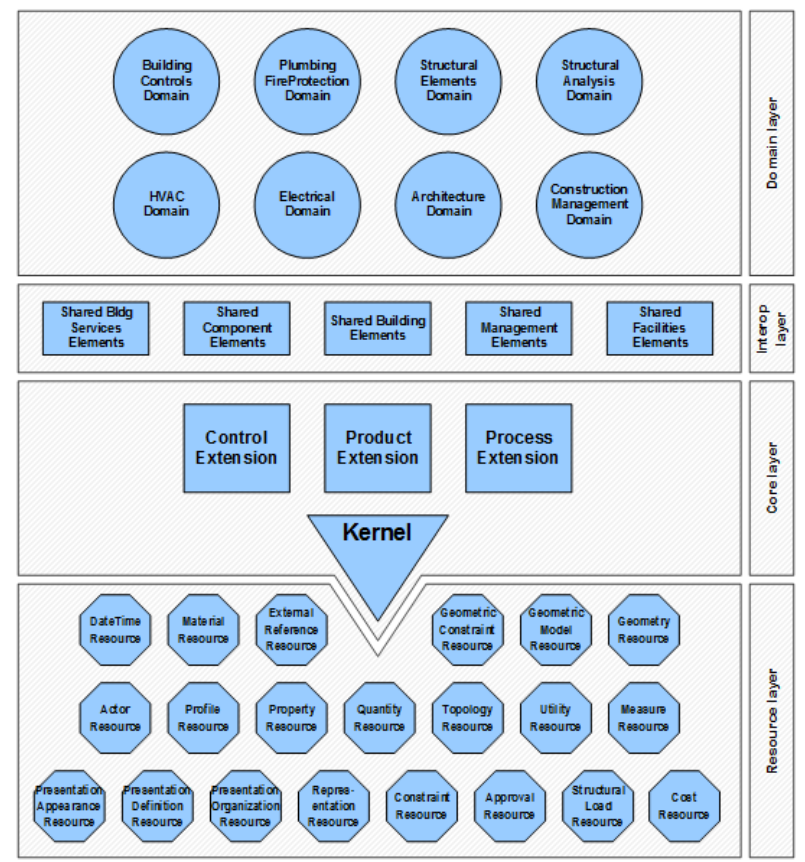

Figure 2 - IFC data schema architecture with conceptual layers (ISO, 2018a)

In this model the external level represents the user's point of view on a specific data model. On the conceptual level, where data models like IFC are defined, independently from software applications, which are implemented on the internal level, with physical schemas. Model views on the model specifying subdomains of interests for IFC are introduced as Model View Definitions (MVD). They are developed starting from an analysis of common task related exchanges and their consequent specification as IFC model view. These specifications are defined thanks to the Information Delivery Manual (IDM) standard, ISO 29481-1:2016. Hence, the use of IFC requires the understanding and combination of its different components, namely IDM, MVD and IFD (International Framework for Dictionary). The standard referred as IFD is the ISO 12006-3 (ISO, 2007) and it offers the specifications for the objectoriented data models for AECO sector, enabling different models to be referenced in a common framework. However, file-based exchanges like IFC have some limitations such as the 
difficult interoperability on instance-level. Also, authoring tools can read IFC models in a read-only mode, making the information process less efficient. BIM servers are technologies that offer the industry the ability to overcome the constraints of the most used file-based technologies of information exchange. The switch of paradigm, from the management of files to the management of object, is the most important principle of serverbased methods. One of the technologies that would ease this change is the Semantic Web and its tools. This term refers to the possibility of enabling both machine and human processing of data on the web, through ontologies, rich semantic representations of concepts in a defined domain. In the last decade researchers have introduced this topic in the AECO sector, as it represents a possible solution for important issues like interoperability, linking across domains and logical inference and proofs (Pauwels, et al., 2017) (Bonduel, et al., 2018), besides consistency checking of semantic models (Barbau, et al., 2012).

A relevant effort for the development of an ontology for the AECO domain is the ifcOWL project, a translation of the EXPRESS IFC schema in OWL (Web Ontology Language) (Beetz, et al., 2009). Three principles guided the translation of the schema:

- Keeping the well-known and established IFC schema for building representation.

- $\quad$ Enabling the features of Semantic Web technologies in the AEC field.

- Exploiting general purpose software implementations for reasoning and knowledge inference applications.

The outcomes of this process also pointed out some of the critical aspects of the IFC schema in its STEP format, in particular the impossibility of converting in OWL the declarations RULE and FUNCTION or LIST data types (Terkaj, et al., 2015). The ifcOWL initiative, though, has not been included in ISO 16739 nor the development process has been reviewed by ISO.

Some other notable ontologies for the AECO sector are: Building Topology Ontology (BOT), a minimal ontology developed by W3C for the representation of topological concepts of buildings (Rasmussen, et al., 2017); Ontology for Property Management (OPM), which allows the possibility of definition of property state (Rasmussen, et al., 2018); RealEstateCore, designed to manage real estate assets information (2); Flow Systems Ontology (FSO), which models energy systems and has already had market applications (3).

\section{ONTOLOGY FRAMEWORK DEVELOPMENT}

For the ontology harmonization, three main topics can be considered: competency question, ontology alignment and ontology evaluation.

Semantic web development has been increased in the last decade. Ontology development plays a significant role in the semantic web. To support ontologies, several methodologies and tools have appeared in the life cycle phases of the ontology. Ontology requirements define as competency questions (CQ's) (Uschold and Gruninger, 1996) in the several methodologies

(2) Source: https://doc.realestatecore.io/3.0/full/index-en.html, accessed on 30/04/2020

(3) Source: https://alikucukavci.github.io/FSO/, accessed on $30 / 04 / 2020$ used for ontology development (Bezerra et al., 2014). CQ's serve as functional requirements in the sense that the developed ontology or an ontology-based information system should be able to answer them (Wisniewski et al., 2018).

"Competency Questions (CQs) are natural language questions outlining and constraining the scope of knowledge represented by an ontology" (Wisniewski et al., 2018).

Ontologies' matching is the process that generates an alignment AI for a pair of ontologies O and OI (Euzenat 2011). To match somethings means, "to bring into line". For given two ontologies aligning one ontology with another means that in the first ontology one tries to find a corresponding entity with the same meaning for each entity (concept, relation, or instance) in the second ontology (Azzam 2013).

Evaluation of ontologies is the task of measuring an ontology's quality. The evaluation can be executed from different views (Vrandecic 2009). As one can see in Figure 3 the Ontology Evaluation Methods (OEM) are in the centre of the evaluation framework. The OEM can be grouped into Ontology Evaluation Criteria (OEC), each of them being part of Ontology Evaluation Perspectives (OEP).

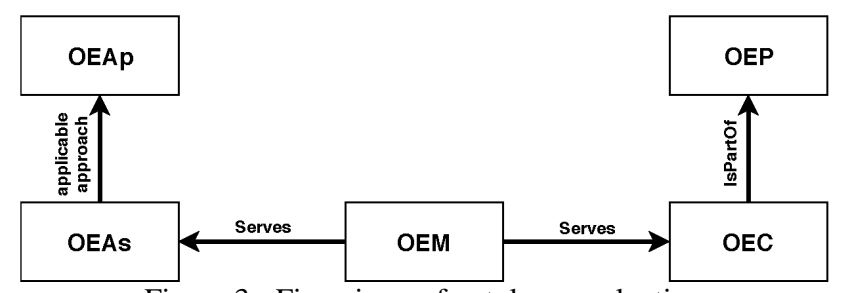

Figure 3 - Five views of ontology evaluation

Complementing to the grouping of OEM in OEC one can use different Ontology Evaluation Approaches (OEAs), again, each of them being applicable to different Ontology Evaluation Aspects (OEAs).

Numerous authors provide recommendations about the necessary steps of ontology development, such as (Sureet al., 2002), (Hartung 2012). In this report, we follow the steps recommended by the latter (Figure 4).

\begin{tabular}{|c|c|c|c|c|c|}
\hline $\begin{array}{c}\text { Determine } \\
\text { scope }\end{array}$ & $\begin{array}{l}\text { Consider } \\
\text { reuse }\end{array}$ & $\begin{array}{c}\text { Enumerate } \\
\text { terms }\end{array}$ & $\begin{array}{l}\text { Define } \\
\text { Classes }\end{array}$ & $\begin{array}{c}\text { Define } \\
\text { properties }\end{array}$ & $\begin{array}{c}\text { Create } \\
\text { Instances }\end{array}$ \\
\hline
\end{tabular}

Figure 4 - Steps for Ontology Development (Hartung 2012)

\section{CASE STUDY: BIM4EEB}

The European project BIM4EEB, part of the Horizon 2020 (H2020) program of the European Community (EC), aims at developing and testing in real environment a BIM toolkit for the renovation operations of existing residential buildings in Europe. Part of this effort has been focused on the development of a framework of ontologies that could, on one side, help managing information exchange during this process, and on the other side provide an example for future exploitation in standardization processes.

In BIM4EEB project, the concept of Semantic Web and the Linked Data paradigm have been introduced to develop technologies or framework which enables more efficient linking and management of heterogeneous data by providing easy access to the data through web platforms. In the construction industry, data are generated from several sources using different tools or applications that involves different roles such as 
architects, manufacturers, designers, etc. creating interoperability and communication issues. At this point, Sematic Web and Linked data approaches enable the efficient interoperability between different applications or tools involved in the AECO industry and this can be ensured by the harmonization of ontologies. The goal of BIM4EEB project is to apply this Semantics and Linked data concepts for achieving efficient data management and data interoperability in the process of existing building renovations. The adopted mechanism for the process of data management and datacarrying is Ontology development (Hartung 2012). It is well known that a plethora of domains, tools, experts, data sources, etc. are involved in the renovation interventions to make the building more sustainable. Since the adopted ideology for the development of ontology should be, not a complete one single ontology for the whole building renovation process, rather it is the development of different modular ontologies with respect to the particular domains. The individual modular ontology is dedicated to the specific knowledge representations of the selected domain. This methodology can enable to organize the involvement of different domain experts and experience professional in the knowledge representations. It also enables individual implementations and ideologies in the development of ontologies. Apart from the ontology development, it is also important to have a realistic paradigm in ontology development.

From the BIM4EEB perspective it is desirable to compile relevant data about the "as built status" of a building before the renovation will start. However, one cannot expect that "as-built data" will be available (or was compiled) over a long operational period in one single, standardised data exchange format or even information model. Thus, there is a need to develop a framework which allows stakeholders involved in a renovation project to efficiently compile, maintain and add data about (i) building elements, (ii) building services systems, (iii) the tenants, operators, and owners of the building, and (iv) the current and predicted performance of the building from the various data sources available.

Over the past three decades a comprehensive "body of knowledge” in open Building Information Modelling has been developed, maintained, and documented by buildingSMART International. One major component is the IFC meta-data model. This model is implemented in different modelling languages, such as EXPRESS, xml, or OWL. However, published versions of this information model do not fully exploit the potential for knowledge management. The expressivity and complexity of available model implementations are high, and consequently the performance of model analysis activities decreases and makes the efficient usage of these models especially for knowledge management tasks (e.g. reasoning) less comfortable.

Therefore, the "Modular Ontology" (Parent et al., 2009) development approach has been chosen that will support the integration of available knowledge repositories, describing the "pre-renovation" status of buildings. Thus, decisions about what and how to renovate can be made faster and in an "informed way". Secondly, it is known from the literature that user behaviour impacts the energy consumption of buildings. Therefore, a substantial part of the ontologies developed in the project focuses on "occupant behaviour modelling" and "user comfort modelling". A third pillar in the development of the BIM4EEB modular ontology is the knowledge management for "workflow and process management". Based on the findings in preliminary tasks of the project a set of Ontologies were developed by the BIM4EEB partners to support specific activities typical for the renovation of residential buildings. This work integrates "third party ontologies" as a whole or in part to maximise the re-use of existing models and concepts. The ontologies developed in this phase of the project will be used in other successive tasks in BIM4EEB. Figure 5 presents a Linked Data Modelling and Sharing Framework based on a "Modularly Networked Set of Ontologies" (Digital Construction Ontologies) consisting of ontologies developed by BIM4EEB (framed part of complemented by ontologies developed by "Third parties" and already well established in the W3community (top part of Figure 5).

To make the developed or existing modular ontologies to be useful, it is essential to align/match existing ontologies and find ways to evaluate ontologies transparently. In a next step we present a set of competency questions which specify the information requirements of Use Case Scenarios specified in the preliminary task of BIM4EEB. This is complemented by a presentation of alignment rules which can be used to integrate relevant concepts of all ontologies, thus contributing to the creation of the BIM4EEB Linked Data Modelling and Sharing Framework. This work mainly explains harmonization of developed and reused ontologies considering the renovation scenario. It is complemented by efforts in the analysis of existing regulation frameworks and recent research efforts. This effort also highlights possible features for a new data exchange standard at European level (CEN TC442).

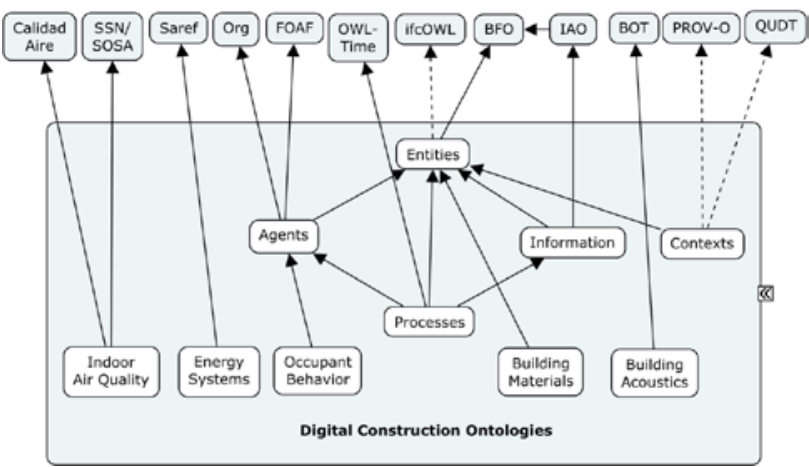

Figure 5 - Digital Construction Ontologies for the BIM4EEBLinked Data Modelling \& Sharing Framework (BIM4EEB, 2020a)

\subsection{Linked Data Modelling and Sharing Framework}

Following the approach described in Section 3, the steps taken for the development of the BIM4EEB-Linked data modelling and sharing framework are:

- Specification of the integration and evaluation methodologies used. Definition of information requirements for the different renovation use cases and related BIM4EEB-tools by formulating Competency Questions,

- investigation of existing ontologies, development of new modular ontologies, and specification of enhancements needed to those ontologies according to the above requirements, and

- harmonization of these ontologies with an emphasis on alignment. 
In the BIM4EEB project, the concept of Competency Questions (CQ) has been adopted in the harmonization process that defines the need and requirements of the domain ontologies. Moreover, these CQ concepts also help to provide a guideline for the new users of the developed ontology. The number of different competency questions are developed along with the data requirements need to represent by ontologies. These competency questions are named according to the work tasks involved in BIM4EEB project with respect to the developed information requirements. Along with this, the following recommendations are taken into consideration in developing the CQ's:

- Avoid Redundancy in the questions.

- Avoid incomplete sentences that cannot be properly understood.

- $\quad$ Avoid sentences that are not really CQ’s.

- Avoid questions beyond the expressive power of a DL-based ontology language (Ren, et al. 2014).

This project develops the competency questions on the following areas: (i) Performance Evaluation System for renovation, (ii) BIM assisted energy refurbishment for renovation, (iii) Occupants profiling mechanism, Web based responsive user interfaces, (iv) Exhaust air heat pumps in the renovation, (v) The design of prefabricated thermal insulation components, (vi) Digital solution to link product data to BIM during the procurement process of a contractor.

For the BIM4EEB-project we recommend using the data driven evaluation approach at the end of the project. The data driven evaluation approach typically involves in the comparison of the ontologies with the needed or specific domain data. In other words, this approach determines if an ontology refers to a specific topic of interest. This method also analyses the ontology efficiency in terms of how far it covers the specific domain.

As there is a plethora of existed ontologies developed for different purposes in the relevant industries, this project has given importance to use these existed ontologies instead of regenerating the knowledge representation. Thus, it reduces the intensive labour work. With this aim numerous ontologies were analysed. Compared to ifcOWL the expressivity and complexity of these ontologies is much lower. Unlike BOT and other ontologies, the IFC schema contains much more ontologies and is structured with a high level of redundancy (Ekholm, 2005). Also, the limits of the language of development are visible in the process of translation into ifcOWL (Beetz, et al., 2009). Out of the total list of analysed ontologies 16 ontologies were selected and integrated either "in total" using the related locator (URL) or just parts of them by integrating the relevant components.

\subsection{Ontology Development and Harmonization}

To develop the modular ontology, the determination of scope of BIM4EEB has considered the following questions:

- What domains will be covered by the ontology?

- For what purpose will the ontology be used?

- What type of informal questions will represent the information managed by the ontology?

- Who will use and maintain the ontology?

- A formulation of competency questions.
Different domains are covered by the presented modular ontologies such as Architecture, Civil Engineering, Construction Management, Mechanical Engineering, and Electrical Engineering. However, the ontology will only cover specific areas from these disciplines such as Human Comfort (architecture), core and shell of buildings (civil engineering), construction works and building material delivery (construction management), HVAC-system (mechanical engineering) and local BAC-systems (electrical engineering). Figure 6 shows the renovation activities covered in BIM4EEB.

In Semantic Networks the usage of an explicit vocabulary is important. The achievements of Building Smart International provide a good starting point for the specification of the vocabulary in BIM4EEB. These specifications cover more than required in BIM4EEB, e.g. vocabulary in different languages, such as English, German, French, Japanese.

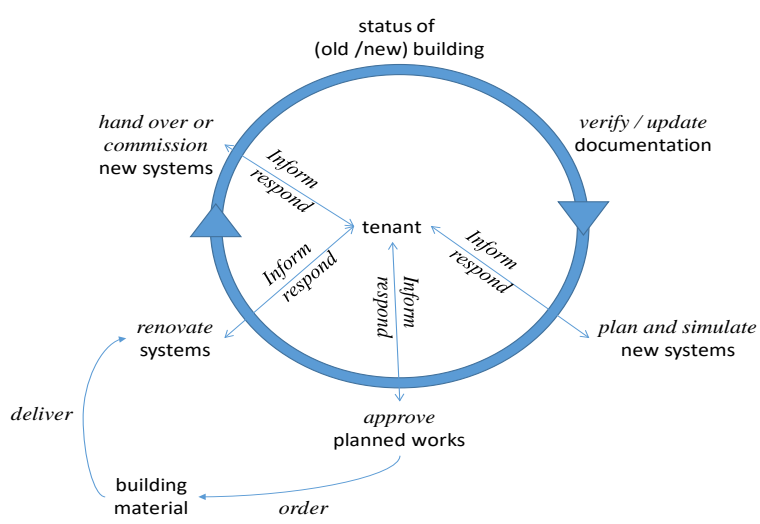

Figure 6 - Renovation activities covered in BIM4EEB

During the ontology development the considerations has been taken on the following questions:

1. What terms shall be included in our BIM4EEB modular ontologies?

2. What properties have these terms?

3. What do we want to specify for these terms?

Ontology alignment provides a solution to the semantic heterogeneity. This considers correspondence between the two ontology entities which semantically have same meaning. This type of alignment has been used for different tasks, such as query answering and ontology merging. In consequence it enables data in the aligned ontology to interoperate. The ontologies developed in BIM4EEB are published on the site:

- Development site: https://github.com/digitalconstruction.

- Publication site: https://digitalconstruction.github.io/

- $\quad$ Permanent id: https://w3id.org/digitalconstruction/

As IFC meta-data model is a very comprehensive information model, to maintain a compatibility with this model an initial alignment between Ontologies has been identified for "reusability in BIM4EEB" and ifcOWL. Such as alignment between REC and ifcOWL, BOT and ifcOWL, OPM and ifcOWL. It is assumed that the availability of such alignments may help in the future to assist users to import relevant data 
from IFC into BIM4EEB ontologies.

As some of the Ontologies identified for re-use in BIM4EEB have overlapping elements, instead of having a need to process alignment exclusively through the usage of ifcOWL, "direct" alignments between selected ontologies has been presented such as alignment between REC and BOT ontologies, BOT and SAREF4BLDG ontologies, FOAF and ORG ontologies. The outcomes of this development are also useful to focus on the weak points of the existing standards for renovation projects.

\subsection{Impacts on Standards}

The harmonization of ontologies in BIM4EEB is also finalized at two goals in the field of standardization: (1) to analyse semantic defects of IFC to be integrated in the existing schema, and (2) to propose improvements of data models thanks to semantic modelling. One of the main causes for interoperability issues is the lack of an explicit theoretical foundation in IFC and building classification systems based on ISO 12006-2 (Ekholm, 2005). The author suggested that the integration of the two standards would provide a well-founded theoretical basis, bringing to an increase in the life span of the standard and a better semantic integration of IFC. An analysis in BIM4EEB framework (BIM4EEB, 2020b), based on the result of Di Martino et al. (2019), showed that also the most recent versions of IFC are based on elements, functional roles and systems defined separately. This strategy hinds the use of external classification systems compliant to ISO 12006-2 (ISO, 2015), and is the main obstacle to define the IFC structure as scientifically well-founded. The BIM4EEB framework of ontologies intends applying the proposed ontologies to the study of three real cases of building renovation, measuring its effects in terms of building and process performances.

\section{CONCLUSIONS}

This paper has been developed in the context of the EU founded project BIM4EEB. It proposes a structured approach to limit the interoperability and communication issues that can be found in the construction processes with a specific reference to renovation operations of existing residential buildings. Starting from the analysis of the state of the art, the research activity here described highlights the need to improve the harmonisation between existing standards and can be used as a useful starting point for future research and activities focused on this scope.

Renovation processes may involve different perspectives and thus require different means to manage the information and knowledge generated during the process itself. Hence the need to move to an ontology-based approach and to combine existing ontologies with a set of ad hoc ones that can satisfy the specific needs of renovation projects. The efforts and results here proposed represents a first step to promote the harmonisation of existing ontology and their match with new developed ones in the context of renovation processes.

These results can be considered for activate working actions both in the analysis of existing standards and in the development of new ones with the scope of creating a more homogeneous and coherent picture. A crucial point that should be considered is the procedural dimension that must guarantee the identification of applicable solutions in the industry context of reference. According to this dimension the BIM4EEB project is identifying specific solutions and will work for the development and validation of these solutions on real case studies to promote the effective and efficient use of the proposed results.

\section{ACKNOWLEDGEMENTS}

This work has been developed in the framework of the EU funded H2020 project BIM4EEB, research and innovation programme, grant agreement N. 820660. We acknowledge Prof. Dr. Karsten Menzel and his research group at Technische Universität Dresden for leading the activities of ontology harmonization, and D.Sc. Seppo Törmä for his work of development of ontologies. The content of this publication reflects only the authors' view and the Commission is not responsible for any use that may be made of the information it contains.

\section{REFERENCES}

ANSI/X3/SPARC, 1975. Interim Report: ANSI/X3/SPARC Study Group on Data Base Management Systems.

Azzam R., Said Rabah and Zhou, Shikun. 2013. "Comparative Analysis of Ontology Alignment Methodology.”

Barbau, R. et al., 2012. OntoSTEP: Enriching product model data using ontologies. CAD Computer Aided Design, 1 6, 44(6), pp. 575-590.

Beetz, J., Leeuwen, J. V. \& Edam, B. D. V., 2009. IfcOWL: A case of transforming EXPRESS schemas into ontologies. Ai Edam, 23(1), 89-101.

Berners-Lee, T., Hendler, J. \& Lassila, O., 2001. The Semantic Web A new form of Web content that is meaningful to computers will unleash a revolution of new possibilities, Scientific American.

Bezerra, C.. Santana, F., Freitas, F., , 2014, "CQChecker: A Tool to Check Ontologies in OWL-DL using Competency Questions written in Controlled Natural Language.”, Learn. Nonlinear Models

BIM4EEB, 2020a. D3.6 Integrated Linked Data Modelling and Sharing Framework.

BIM4EEB, 2020b. D3.7 Definition of harmonised common data exchange formats and integration of open-BIM data standards for sharing information.

BIM4EEB, 2019. BIM4EEB : BIM based toolkit for Efficient rEnovation in Buildings. [Online] Available at: https://www.bim4eeb-project.eu/

Bonduel, M. et al., 2018. The IFC to Linked Building Data Converter-Current Status, In 6th Linked Data in Architecture and Construction Workshop (Vol. 2159, pp. 3443).

Di Martino, B., Mirarchi, C., Ciuffreda, S., \& Pavan, A. , 2019. Analysis of Existing Open Standard Framework and Ontologies in the Construction Sector for the Development of Inference Engines. In Conference on Complex, Intelligent, and Software Intensive Systems (pp. 837-846). Springer, Cham.

Eastman, C. M., Teicholz, P. M., Sacks, R. \& Lee, G., 2018. BIM handbook : a guide to building information modeling for owners, managers, designers, engineers and contractors. Publisher: John Wiley \& Sons Inc, 3rd ed.

Ekholm, A., 2005, ISO 12006-2 and IFC prerequisites for coordination of standards for classification and interoperability. Journal of Information Technology in Construction (ITcon), 10(19), 275-289.

Euzenat, J. et al., 2011. Ontology alignment evaluation initiative: Six years of experience. In: Lecture Notes in Computer Science (including subseries Lecture Notes in Artificial Intelligence and Lecture Notes in Bioinformatics). s.l.:Springer Verlag, pp. 158-192. 
Hartung, M., 2012. Ontologie Management Kapitel 4: Erstellung von Ontologien, Leipzig: Universität Leipzig, Institut für Informatik.

ISO, 2004a. ISO 10303-11:2004 - Industrial automation systems and integration - Product data representation and exchange - Part 11: Description methods: The EXPRESS language reference manual. [Online] Available at: https://www.iso.org/standard/38047.html

ISO, 2004b. ISO 15926-1:2004 - Industrial automation systems and integration - Integration of life-cycle data for process plants including oil and gas production facilities - Part 1: Overview and fundamental principles. [Online] Available at: https://www.iso.org/standard/29556.html

ISO, 2007. ISO 12006-3:2007 - Building construction - Organization of information about construction works - Part 3: Framework for object-oriented information. [Online]

Available at: https://www.iso.org/standard/38706.html

ISO, 2015. ISO 12006-2:2015 - Building construction - Organization of information about construction works - Part 2: Framework for classification. [Online] Available at: https://www.iso.org/standard/61753.html

ISO, 2018a. ISO 16739-1:2018 - Industry Foundation Classes (IFC) for data sharing in the construction and facility management industries - Part 1: Data schema. [Online]

Available at: https://www.iso.org/standard/70303.html

ISO, 2018b. ISO 19650-1:2018 - Organization and digitization of information about buildings and civil engineering works, including building information modelling (BIM) - Information management using building information modelling - Part 1: Concepts and principles. [Online]

Available at: https://www.iso.org/standard/68078.html

Lee, G., 2011. What Information Can or Cannot Be Exchanged?. Journal of Computing in Civil Engineering, 25(1), 1-9.

Liu, Z., Lu, Y. \& Peh, L. C., 2019. A review and scientometric analysis of Global Building Information Modeling (BIM) Research in the Architecture, Engineering and Construction (AEC) industry. s.l.:MDPI AG.

Mirarchi, C., 2019. Knowledge network for innovation ofconstruction sector - Increasing efficiency through process digitisation of the entire chain,

NBS, 2019. National BIM report 2019, Available at: https://www.thenbs.com/knowledge/national-bimreport-2019

Parent, C., Spaccapietra, S. 2009. “An Overview of Modularity.” In Modular Ontologies, by Heiner Stuckenschmidt, Christine Parent and Stefano Spaccapietra, 5 to 24. Berlin, Heidelberg: Springer.

Pauwels, P., Zhang, S. \& Lee, Y. C., 2017. Semantic web technologies in AEC industry: A literature overview. s.l.:Elsevier B.V..

Rasmussen, M. H. et al., 2017. Recent changes in the Building Topology Ontology. Procedings of the 5th Linked Data in Architecture and Construction Workshop (LDAC), Issue November, p. 7.

Rasmussen, M. H. et al., 2018. OPM: An ontology for describing properties that evolve over time, In CEUR Workshop Proceedings (Vol. 2159, pp. 24-33). CEUR Workshop Proceedings.

Sure, Y., S. Staab, and R. Studer. 2002. "Methodology for Development and Employment of Ontology based Knowledge Management Applications.” Sigmod Record $31((4))$.
Terkaj, P., Krijnen, W. \& Beetz, T. F., 2015. Coping with lists in the ifcOWL ontology. In 22nd EG-ICE International Workshop (pp. 113-122).

Uschold, M., Gruninger, M. 1996. "Ontologies: Principles, methods and applications.” The knowledge engineering review (Cambridge University Press) 11 (2): 93-136.

Vries, A. P. d. (. P., Apers, P. M. G. \& University of Twente, 1999. Content and multimedia database management systems. s.l.:Centre for Telematics and Information Technoloy (CTIT).

Vrandecic, D. 2009. “Ontology evaluation.” In Handbook on Ontologies | International Handbooks in Information Systems, by S. Staab and R. Studer, 293 to 313. Berlin, Heidelberg: Springer.

W3C, 2014. Linked Building Data Community

Group. [Online]

Available at: https://www.w3.org/community/lbd/

Wisniewski, D., Potoniec, J., Lawrynowicz, A. and Keet, C M. 2018. "Competency questions and SPARQLOWL queries dataset and analysis." arXiv preprint arXiv:1811.09529.

Won, J. et al., 2013. Where to Focus for Successful Adoption of Building Information Modeling within Organization. Journal of construction engineering and management, 139(11), 04013014. 